TITLE PAGE

\title{
Population-based Genetic Testing for Women's Cancer Prevention
}

\section{AUTHORS}

Olivia Evans ${ }^{1,2}$, Faiza Gaba ${ }^{1,2}$, Ranjit Manchanda ${ }^{1,2,}$

${ }^{1}$ Wolfson Institute of Preventive Medicine, Barts CRUK Cancer Centre, Queen Mary University of London, Charterhouse Square, London, EC1M 6BQ, UK

${ }^{2}$ Department of Gynaecological Oncology, St Bartholomew's Hospital, London, UK, EC1A 7BE

*Corresponding Author: Professor Ranjit Manchanda, MRCOG, PhD

Wolfson Institute of Preventative Medicine, Barts CRUK Cancer Centre, Queen Mary University of London, Charterhouse Square, London EC1M 6BQ, UK

Email: r.manchanda@qmul.ac.uk

Tel: 00447979884575 


\section{ABSTRACT}

Germline mutations in cancer-susceptibility-genes (CSG) can dramatically increase women's lifetime risk of ovarian, endometrial, breast and bowel cancers. Identification of unaffected carriers is important to enable proactive engagement with highly effective screening and preventive options to minimise cancer risk. Currently a family-history model, is used to identify individuals with CSGs. Complex regional referral guidelines, specify the family-history criteria required before an individual is eligible for genetic-testing. This model is ineffective, resource intense, misses $>50 \%$ CSG carriers, is associated with underutilisation of genetic-testing services and delays detection of mutation carriers. Although awareness and detection of CSG-carriers has improved, over $97 \%$ carriers remain unidentified. This reflects significant missed opportunities for precision-prevention. Population-based genetic-testing (PBGT) represents a novel healthcare strategy with the potential to dramatically improve detection of unaffected CSG-carriers along-with enabling population risk-stratification for cancer precision-prevention. Several research studies have assessed the impact, feasibility, acceptability, long-term psychological outcomes and cost-effectiveness of population-based BRCAtesting in the Ashkenazi-Jewish population. Initial data on PBGT in the general-population is beginning to emerge and large implementation studies investigating PBGT in the general-population are needed. This review will summarise the current research into the clinical, psycho-social, health-economic, societal and ethical consequences of a PBGT model for women's cancer precision-prevention.

\section{KEYWORDS}

BRCA, Population-Based Genetic Testing, Cancer, Ovarian, Breast, Endometrial, Lynch Syndrome

Word Count $=9005$ 


\section{HIGHLIGHTS}

- Population-based Genetic Testing identifies more unaffected mutation carriers than current clinical strategies

- Founder populations have demonstrated high acceptability of PBGT

- Unselected BRCA testing in the Jewish population is feasible, has high satisfaction, doesn't harm psychological wellbeing or quality of life, reduces anxiety and is potentially cost-saving.

- Economic modelling suggests PBGT reduces cancer incidence and is cost-effective

- Future work should focus on multi-panel cancer susceptibility genes testing, and use of complex cancer prediction algorithms for risk-adapted population stratification and precision prevention. 
Units and Abbreviations

\begin{tabular}{|l|l|}
\hline $\boldsymbol{A T M}$ & ATM serine/threonine kinase \\
\hline BRCA1 & Breast Cancer Gene Type 1 \\
\hline BRCA2 & Breast Cancer Gene Type 2 \\
\hline BRIP1 & BRCA1 interacting protein C-terminal helicase 1 \\
\hline CDH1 & Cadherin 1 \\
\hline PALB2 & Partner and localizer of BRCA2 \\
\hline PARP & Poly ADP-ribose Inhibitor \\
\hline RAD51C & RAD51 paralog C \\
\hline RAD51D & RAD51 paralog D \\
\hline STK11 & Serine/threonine kinase 11 \\
\hline TP53 & Tumor protein p53 \\
\hline
\end{tabular}




\section{INTRODUCTION}

An individual's genetic background influences many aspects of carcinogenesis. Subsequently, the evolving clinicopathological characteristics of tumours have their origins within genetics. Classically, highly penetrant cancer-susceptibility genes (CSG) have been the focus of oncogenetic research. The most well-defined are BRCA1 and BRCA2 mutations which disturb the cellular DNA repair pathway. Knowledge of a cancer patient's genetic landscape has been utilized primarily for targeting cancer therapy through 'Precision Medicine' approaches. A classic example is PARP inhibitors which disable tumours affected by dysfunctional $B R C A$ pathways in $B R C A 1$ and $B R C A 2$ mutation carriers. Olaparib as first line maintenance therapy significantly improves progression free survival in BRCA-mutated ovarian cancer.[1] BRCA testing is now advocated for all high-grade non-mucinous epithelial OC patients. However, the maximum impact on burden of cancers in the population from CSG identification is likely to come not from targeted therapies but from 'Precision Prevention'. 'Precision Prevention' is a prevention strategy which incorporates individual variability in non-genetic (e.g. environment, epidemiologic, hormonal, lifestyle, behavioural), as well as genetic and even epi-genetic risk-factors. This comprises both primary prevention (disease prevention) and secondary prevention (screening/early-detection).

Breast, ovarian and endometrial cancer constitute $40.1 \%$ of all female cancers in the UK, representing $71^{\prime} 605$ new cases in 2016[2]. Although cancer treatment is improving these three cancers still resulted in 17 '775 deaths in 2017[2]. Germline mutations in CSGs contribute to a significant minority of these cases (3\% of Endometrial, 6\% Breast, 15-20\% OC)[3-6]. Although with increasing awareness and accessibility, those with cancer are more likely than ever to receive genetic testing, there is still massive under-utilisation of genetic services with some studies suggesting only $20 \%$ of eligible individuals access testing.[7] Additionally, identification of CSG carriers before they develop cancer remains extremely limited. Crucially, early recognition enables women to proactively participate in 
high-risk screening programs, chemoprevention and risk-reducing surgery. These clinically effective preventative strategies have a substantial impact in reducing the morbidity and mortality of women's cancers[8-11]. Furthermore, knowledge of carrier status provides opportunity for making lifestyle and reproductive choices, preimplantation genetic diagnosis during family planning as well as cascade testing in other unaffected relatives.

In the United Kingdom (UK) National Health Service (NHS), conventional access to genetic testing is based on a family-history model (FHM) with individuals with a $\geq 10 \%$ probability of carrying a $B R C A$ mutations offered $B R C A$ testing[12]. Similar thresholds exist in many other health systems. However the FHM has been acknowledged to have several limitations[13]. Inequality exists for unaffected individuals at every stage of the FHM. It requires healthy individuals to be aware of their family history spanning across three generations (both maternal and paternal) and for them and their doctor to comprehend its significance. This requires understanding of genetic inheritance and hereditary cancers. Awareness of CSGs is greater in higher socio-economic groups, Caucasian populations and founder populations such as the Ashkenazi Jewish population [14-19]. Furthermore, those with small family units, those with estranged, adopted or families dispersed due to migration lack the ability to identify this clustering and are disadvantaged. For genes which predispose to women's cancers, male predominance and paternal inheritance (or pure chance) may conceal its visibility through generations[20]. Similarly, those who have a de novo germline mutation will lack an appropriate family history[21, 22]. Research suggests $50-60 \%$ of patients with a BRCA mutation are not eligible for genetic-testing and are missed through the FHM[23-25]. Complex referral guidelines exist for those with familial cancer clusters, and acceptance to genetic services is dependent on clinical testing criteria and risk algorithms[26-30]. As a result of the aforementioned limitations, only $2.6 \%$ of $B R C A$ carriers in Greater London have been detected with a FHM[31] and detection of other CSG such as Lynch Syndrome is worse still, with a US study estimating only $1.2 \%$ of carriers are aware of their diagnosis[32, 33]. 
Population-based genetic testing (PBGT) for CSGs is a novel healthcare initiative. In principle, this involves unselected genetic testing being available to the general population irrespective of family history. This has the potential to overcome the limitations of the FHM and increase carrier ascertainment maximising the access to precision-prevention approaches. Additionally, it enables population stratification by cancer risk (beyond just CSGs) for targeted risk adapted screening and prevention. Complex risk models which incorporate validated common genetic variants or single nucleotide polymorphisms (SNPs) along with non-genetic epidemiologic/hormonal data with/without moderate-high penetrance genes can be used to predict personalised lifetime risk estimates for targeting screening/preventive interventions of therapeutic benefit.

Wilson and Jungner outlined the ten principles of screening for disease in 1968. The UK National Screening Committee has published updated criteria for its national screening programmes[34]. Additionally new emerging criteria regarding integration of education and clinical services, confidentiality, equality and self-evaluation, analytic/clinical validity, clinical utility, ethical/legal/social implications, cost-effectiveness[35-38] require consideration. These frameworks provide focus and structure in the analysis of PBGT for precision prevention.

A growing body of research is addressing the feasibility, acceptability, cost-effectiveness and psychological outcomes of PBGT. The vast majority of data comes from unselected BRCA testing in the Ashkenazi Jewish population[20, 23, 25, 39, 40]. More recent ongoing research studies within lowrisk, unaffected cohorts are providing initial data on the ongoing ethical, psychological, logistical and clinical considerations for PGBT[41, 42].

WHAT IS THE PREVALENCE AND RISKS OF CANCER SUSCEPTIBILITY GENES FOR WOMEN'S CANCER? 
Fundamentally, in Wilson and Jungner's criteria, the epidemiology of the condition must be well understood and represent a significant health burden. The $B R C A$ genes were discovered $\sim 25$ years ago the precise cancer risk associated with them has evolved. Initial overestimates originated from enriched family clusters were the gene was first identified.[43, 44] However, subsequent analyses have corrected for ascertainment and estimate the cumulative lifetime risk at 80 years for breast cancer (BC) is $72 \%$ for $B R C A 1$ and $69 \%$ for $B R C A 2$ respectively[45]. The cumulative ovarian cancer (OC) risk is, $44 \%$ for $B R C A 1$ and $17 \%$ for $B R C A 2[45]$. International data regarding Lynch Syndrome, caused by mutations in mismatch repair genes have outlined the lifetime risk of endometrial cancer to range from $43-57 \%$ and $O C$ to range from $10-17 \%$ with $M L H 1 / M S H 2 / M S H 6$ mismatch repair mutation carriers. In addition these genes are associated with an increased risk of colorectal cancer ranging from 15-46\%.[46] More recently, moderate-penetrance OC gene-mutations such as, RAD51C (lifetime OC-risk 11.2\%),[47] RAD51D (lifetime OC-risk 11.9\%)[48] and BRIP1 (lifetime OC-risk 5.8\%)[49] were identified and validated. Additionally PALB2 has emerged as a high risk BC (lifetime BC-risk 53\%) and moderate risk OC (lifetime OC-risk 5\%) gene.[50] In principle, these genes have established clinical utility as their cancer risks are above the risk threshold at which an effective clinical intervention of therapeutic benefit is available to reduce risk and prevent cancers in unaffected individuals.

BRCA1/2 mutations are responsible for $~ 15 \%$ OCs[51] and 5\% BCs[52] in general-population women and for $30-40 \% \operatorname{OCs}[53,54]$ and $10 \% \operatorname{BCs}[55]$ in AJ women. Non-BRCA1/2 mutations of clinical utility probably account for around another $2.5 \%$ OCs $[56,57]$ and $1 \%$ BCs. $[51,52]$

BRCA1/2 mutations effect $\sim 1: 150$ to $1: 200$ members of the general population, [58, 59] with Lynch Syndrome affecting 1:370[60]. Global variation exists and certain communities contain a higher prevalence. The Ashkenazi Jewish (AJ) population harbours three BRCA founder mutations (BRCA1 5382insC, 185delAG mutation, and BRCA2 6174delT). These historical genetic changes are present in 
$\sim 1: 40$ of this community[25, 40, 61, 62]. This high prevalence has prompted five trials to conduct PBGT for founder mutations in these communities.

\section{POPULATION-BASED TESTING OF BRCA FOUNDER MUTATIONS USING THE JEWISH MODEL}

Richards et al conducted an initial pilot study in Texas, recruiting 309 AJ participants in 1997[39]. This group tested only for the 185DelAG BRCA1 mutation which was validated in 1996, later testing for the BRCA2 mutation. Six BRCA1 \& seven BRCA2 pathogenic variants were detected. This resulted in a higher than expected incidence of $4.2 \%$. However this sample was enriched with families affected by $\mathrm{BC}$ or OC constituting a selection bias. Hartge et al tested 5318 men and women in the Washington Ashkenazi Study in 1996 and found a founder mutation prevalence of 2.3\%.[63]

The Polish 'Twoj Styl' study tested 5024 for three founder BRCA1 mutations common in Poland[64]. Novel recruitment via a one-time advert in a popular magazine was extremely successful with 5024 respondents undergoing genetic testing. 3.9\% BRCA1 carriers were identified. Although recruited via a population-based advertisement, the inclusion criteria and ascertainment was biased by family history, as it required participants to have a personal or family history of $\mathrm{BC}$ or $\mathrm{OC}$. Therefore, this was not true population based testing and the findings are not comparable to PBGT.

Metcalfe et al. recruited 6108 Canadian Jewish women in a PBGT study[20,65]. Although the group did not exclude those with personal history of $\mathrm{BC}$ or $\mathrm{OC}$, a very low proportion of participants had a personal history recorded. This may explain the detection rate of $1.1 \%$ (68 carriers) which is lower than the expected $2.5 \%$ incidence within AJ communities[61, 62]. 
Gabia-Kapara et al. conducted the largest study recruiting 8195 unaffected Israeli men in an attempt to avoid selection bias[25] and estimate penetrance. Participants were recruited from general medical clinics irrespective of family history of cancer. The study identified 175 pathogenic mutations, resulting in a detection rate of $2.17 \%$.

Manchanda et al. published the first randomised control trial, comparing PBGT to FHM. Recruitment of 1042 AJ participants occurred via religious charities and community groups, with $89 \%$ consenting to genetic testing[23]. This study analysed Ashkenazi Jewish founder BRCA detection for 504 participants in a FHM-arm compared to a 530 participants randomly allocated to the PBGT-arm. Within the PBGT-arm all participants received genetic testing and 13 participants were found to have pathogenic mutations (incidence $2.45 \%$ ). After three-years of follow-up was completed, the family history negative participants in the FHM-arm were offered genetic testing, and a further $8 B R C A$ carriers identified. The total incidence was therefore 30/1034 (2.9\%)[40].

\section{Does PBGT detect more pathogenic variants than a Family History Model?}

The Jewish population based studies provide strong evidence that PBGT is more effective than the FHM for BRCA detection in unaffected carriers. Manchanda et al found that overall, 18 of the 30 pathogenic carriers detected were not eligible for family-history based testing according to current clinical criteria and would have been missed[40].

Metcalfe et al. also compared FHM referrals to the Toronto genetic clinical services over the same time period (2007-2012) as their PBGT study[65]. 192/437 FHM referrals were eligible for testing and 22 carriers identified (11.5\%). However, PBGT was more effective in identifying unaffected carriers (n = 92) than the FHM $(n=29)$. 
Gabai-Kapara also reported family history characteristics of participants. Participants were defined as 'high incidence families' if they contained a case of pre-menopausal $B C, \geq 3 \mathrm{BC}$ at any age, any male $\mathrm{BC}$ or any OC. Based on current UK criteria these families would be able to access genetic testing through the FHM. Low incidence families did not meet any of the criteria listed. Of the mutation carriers in this PBGT study, $49 \%$ were from high incidence families (family history positive) but $51 \%$ were from low incidence families (family history negative)[25]. Similar corroborating data are available from unselected genetic testing at cancer diagnosis[66] and return of secondary findings in larger general population cohorts[59] where $50 \%$ of carriers identified would not have met genetic testing criteria. Together, these studies demonstrate that PBGT enables more effective detection of unaffected BRCA carriers than a FHM.

\section{DECTECTION OF OTHER CSG IN THE GENERAL POPULATION USING PBGT MODEL}

The fall in the cost of genetic testing and the availability of next generation sequencing has prompted a rise in the use of 'multi-gene panel' testing, where multiple genes are analysed simultaneously. There is significant variability regarding which genes are offered on panel testing in clinical practice[67]. The ACCE model regarding analytical and clinical validity should be adhered to in selecting appropriate gene panels which contain only genes with clinical utility[68]. Recently validated OC CGSs include RAD51C, RAD51D, BRIP1, PALB2, associated with lifetime risk 5-11\%[50, 69, 70] and have been included in several recent PBGT studies.

Rowley et al. 2018 published an Australian study of 5908 unselected women, recruited from a government funded breast screening programme[71]. Although population-based in selection, this study was not specifically designed for PBGT, genetic testing was added as a 'bolt-on'. Patients were not recruited for this purpose. This 'bolt-on' model of returning additional 'secondary-findings' is not 
the same as analysing the prospective uptake of population genetic testing for genes of established clinical utility based on principles of population screening. This group use a multi-gene panel of eleven CSG (BRCA1, BRCA2, PALB2, ATM, CDH1, PTEN, STK11, TP53, BRIP1, RAD51C and RAD51D) which have a range of accompanying risks of breast and OC[72-74]. Overall, incidence of pathogenic mutation incidence was $1.77 \%$ ( $0.64 \%$ in high-risk genes and $1.13 \%$ in moderate risk genes respectively). Participants with a family history of $\mathrm{BC}$, are more likely to have participated in Rowley et al. study inadvertently leading to a selection bias. This is evidenced in the familial characteristics of the 38 participants with pathogenic variants. Twenty-four had a first-degree relative with BC or OC. As this study was not designed primarily for PBGT, it is difficult to draw strong inferences apart from some estimates of mutation prevalence. These studies show acceptability of returning clinically relevant genetic research results or secondary findings and are supportive of the concept of broadening access towards a population-based approach. However, they do not address in a prospective unbiased fashion key questions around delivery and impact of population testing.

An unpublished UK pilot study, PROMISE-FS assessed the feasibility of PBGT using a panel of CSGs (BRCA1, BRCA2, RAD51C, RAD51D, BRIP1) in combination with OC-SNP polygenic risk scores and epidemiological risk factors to increase precision of risk estimates to predict lifetime ovarian cancer risk and stratify a low risk unaffected population into risk categories (low/intermediate/high) as well as offer appropriate downstream management[42]. This study will provide important insights into the feasibility and acceptability of PBGT in unselected women for multigene testing and predicting lifetime ovarian cancer risk.

Regarding low-risk general population studies, the ongoing Canadian 'Screen Project' is offering PBGT for BRCA1 and BRCA2 for $\$ 165$ in a direct-to-consumer model. Initial commentary reported a detection rate of $3.3 \%$ among the initial 150 participants[41]. Three of the five detected pathogenic 
mutations, did not meet criteria for testing in a FHM [41]. However, direct-to-consumer models currently offered by commercial companies are biased by a potential healthy volunteer effect and may have a higher ascertainment rate due to individuals aware of a strong family history being more likely to undergo testing.

\section{WHAT TYPE OF GENETIC COUNSELLING IS APPROPRIATE FOR PBGT?}

Genetic counselling is recommended by international consensus prior to and following genetic testing. Pre-test genetic counselling provides risk awareness and helps patients understand their genetic testing options and potential outcomes. Post-test counselling helps patients understand the results, and the medical implications. This is a resource intense and time-consuming process.

In order for the successful implementation of PBGT, novel alternatives must be explored to avoid overwhelming current genetics services. Research studies have explored group sessions, DVD-based approaches, telephone and telemedicine consults as alternatives approaches and found non-inferior with similar patient satisfaction[75]. A DVD method was found to be non-inferior and deliver costsavings of $£ 14 /$ volunteer compared to a traditional approach [76]. Unsurprisingly, PBGT studies have adopted a variety of methods.

It is important to differentiate 'patient education' from 'counselling', two concepts which are often intertwined. Most PBGT studies have prioritising the educational focus and did not provide any pretest counselling $[64,65]$. This risks neglecting the core counselling element which explores the concerns and expectations of genetic testing. Richards et al. provided community pre-test counselling in group sessions (50 participants per-session)[39]. In comparison, Manchanda et al. provided traditional pre-test counselling to all participants in the randomised control trial. Pre-test counselling 
was found to increase awareness of disadvantages of $B R C A$ testing, influencing the final cost-benefit perception and decision-making on undergoing testing.[18]

Metcalfe et al. compared counselling work-load per pathogenic mutation, in PBGT (average $=2.6$ hours) versus FHM (average $=12.7$ hours) demonstrating the significant clinical burden of the traditional method[65]. At one year following PBGT 56\% of carriers and $19 \%$ participants overall retrospectively wished they had received formal pre-test counselling[77]. A pilot UK study demonstrated feasibility of using a web-based decision aid and telephone helpline for population testing feasibility of this approach[78] and a recent AJ population study has also used an online pretest education and consent process.[79]

Most studies opted to provide individual face-to-face post-test counselling for those with pathogenic mutations or very strong family histories. Rowley et al. was the only study to not conduct this.

\section{WHAT ARE THE CLINICAL CONSEQUENCES FOR THOSE IDENTIFIED WITH A CSG THROUGH PBGT?}

\section{Risk-reducing strategies}

A key question is whether women with a pathogenic variant detected though PBGT have the same health behaviours as those detected traditionally through FHM. Personal and family experience of cancer is a fundamental motivator in participating in risk-reducing strategies[80]. Therefore, it could be hypothesised that PBGT detection may result in less proactive clinical decision making. Data on this are limited but emerging and appear reassuring. Metcalfe et al. reported $100 \%$ uptake of breast screening, $90 \%$ incidence of risk-reducing salpingo-oophorectomy (RRSO), $11 \%$ rate of risk-reducing mastectomy (RRM) in PBGT-detected carriers, rates similar to Canadian population norms[81]. 
Rowley et al. reported $46 \%$ of the BRCA mutation carriers opted for RRSO. At the time of publication, none had chosen bilateral risk-reducing mastectomy[71]. The uptake of RRM is lower than reported levels in those detected via $\mathrm{FHM}[81,82]$. However, this may reflect the longer median time to surgery from diagnosis for RRM than RRSO[83] as well as the short follow-up time available for population based studies. Furthermore, internationally only $3.4 \%$ of RRM were conducted in women over 60 years old, close to the mean age (59.2 years) of Rowley cohort[82].

Notably Rowley et al did not inform participants of pathogenic variants in moderate risk genes (RAD51C, RAD51D, BRIP1) which increased the risk of OC by $5-11 \%[84]$. The threshold for OC prophylactic surgery has been defined to be $4-5 \%$ therefore, carriers of these moderate risk genes would have potentially benefited from RRSO.

\section{Cascade Testing}

Once a pathogenic mutation is identified, individuals are invited to refer at risk relatives for genetic testing; a process referred to as cascade testing. The impact of PBGT on this practice has been reported by several studies. Rowley et al. noted the number of relatives referred for cascade testing did not differ in those identified in PBGT (referred 3.3 relatives) compared to local FHM norms (3.1 referred) [71]. Similarly, Gabai-Kapari reported an average of 3.7 relatives referred per mutation identified[25]. Thus far, pro-band detection via PBGT doesn't appear to affect cascade testing in the AJ population. However as increasing data becomes available, it is likely that the rate of cascade testing will increase as current uptake is limited by number of identified carriers through these studies. However, this does highlight an important point that PBGT needs to be accompanied by public health campaigns to raise awareness of unselected testing and its benefits.

\section{False reassurance effect}


The 'false reassurance effect' involves the welfare of individuals who undergo PBGT but are found not to carrier a mutation. There exists a theoretical concern these non-carriers may be incorrectly dissuaded from attending national screening or seeking medical advice for cancerous symptoms. Richards et al. reported no significant difference in the rate of mammography attendance in noncarriers in the years following negative result ( $88.3 \%$ in year $1,91.7 \%$ in year 2$)$. Although, notably this cohort was highly educated with $50 \%$ attaining graduate level education [85]. Data on long-term health behavioural outcomes related to uptake of routine screening programmes in those testing negative following PBGT is limited and more research into the subsequent health-behaviours of this cohort is required.

\section{WHAT ARE THE PSYCHOLOGICAL CONSEQUENCES OF PBGT?}

The psychological impact of PBGT has been assessed by two of the published trials. Metcalfe et al. monitored cancer-related distress in 2074 participants undergoing PBGT for BRCA mutations. The impact of events scale was used to measure this variable pre-testing and one year following. For noncarriers there was no significant difference. However, for BRCA mutation carriers cancer-related distress was significantly higher at one year post results[77]. This cancer-related distress had returned to low pre-test values at 2-years following PBGT diagnosis. Although, limited participants completed questionnaires at all three time intervals (number $=19$ ), exploratory findings suggest that risk-reducing surgery is fundamental in improving cancer-related distress[81]. Lieberman et al in a study of 1771 participants also found that at 6 months, carriers had significantly increased distress and anxiety, greater knowledge, and similar satisfaction as non-carriers.[86] The Metcalfe and Lieberman studies lacked a control arm and did not provide pre-test counselling. 
Manchanda et al used a variety of validated questionnaires to compared quality of life, anxiety, depression, health anxiety, impact of testing and cancer-worry between PBGT and FHM in a randomised design[23]. These variables were measured at baseline, 7 days, 3 months and at yearly intervals until 3-years following diagnostic results. Over three years, the participants in the PBGT-arm had a statistically significant decrease in anxiety and total anxiety and depression scores compared with the FH-arm over 3 years. Otherwise, there was no statistical difference in other psychological or quality-of-life variables between PBGT and FHM[23] testing strategies. All participants in this study received pre-test genetic-counselling. All studies reported high satisfaction rates of $90-95 \%$.

There is currently no published literature on the psychological effects of PBGT for CSG in a low-risk non-Jewish general population. The results of the PROMISE feasibility study which has investigated psychological outcomes following PBGT are awaited[42].

\section{FACILITATORS AND BARRIERS TO PBGT?}

Being married/cohabiting is associated with a four-fold higher odds of uptake of genetic testing.[18] Higher levels of BRCA-related knowledge and lower anxiety was positively associated with uptake of genetic testing. Perceived benefits have been associated with greater interest and intention but not necessarily uptake of genetic testing.[18] Genetic discrimination by employers and insurance organisations is a greater concern in societies with private healthcare systems[87]. Regarding women's cancer prevention a minority of AJ participants declined PBGT on account of this reason in privatised (US)/semi-privatised (Israel) healthcare systems [25, 39]. Qualitative research has demonstrated more pressing social concerns centre around community discrimination, for example reduced marriage prospects [88]. A small but not insignificant proportion (3-13\%) of individuals felt PBGT may increase anti-Semitism $[88,89]$. Data from the population based UK study showed that 
increased levels of concern associated with singling out an ethnic group, stigmatisation and marriage ability were associated with significantly lower interest/intention and lower odds of uptake of $B R C A$ testing.[18] Concerns regarding confidentiality, insurance, emotional impact are associated with lower uptake of BRCA-testing. Despite these concerns, overall PBGT testing for BRCA mutations appears acceptable in Jewish communities, $90-95 \%$ participants felt genetic testing should be available to all Jewish women[77]. Overall the facilitators and barriers to PBGT appear similar to those found in high risk women undergoing testing through cancer genetics clinics.

Further research regarding unaffected population opinions of PBGT in non-Jewish and ethnic minority populations would be beneficial. It will be important to elicit specific cultural concerns prior to implementation, so counselling and education can be tailored as appropriate to ensure PBGT programmes are inclusive.

\section{VARIANTS OF UNKNOWN SIGNIFICANCE}

The majority of PBGT studies for founder BRCA mutations were detected by polymerase chain reaction, or specific exon analysis $[20,23,25,39]$. PBGT in a low-risk general population requires very different processing due to national diversity and the vast array of unique mutations. Genes are analysed by next-generation sequencing (NGS) which involves much greater analytical detail. Interpretation is more complex, partially due to the higher incidence of variants of unknown significance (VUS)[90]. These represent genetic anomalies which currently cannot be identified as pathogenic or benign. Pervasive racial disparities in genomic medicine can lead to more frequent VUS results for black and ethnic minority populations[91-93]. Additionally VUS rates will increase with the number of genes included in a test. 
Contrary to current clinical practice, PBGT trials have not informed participants of VUS results. This is due to academic concerns they would evoke unnecessary confusion, potentially increased anxiety and lead to misinterpretation leading to inappropriate management or unnecessary clinical interventions[94]. However, as genomic technologies evolve and more variant data accumulate, it is inevitable a proportion of PBGT results will be reclassified from VUS to pathogenic. Logistically the clinical responsibility of informing patients and managing these variants in the long-term must be accounted for in healthcare frameworks. The public must be aware about the potential for results to change many years after PBGT. Clarity regarding medicolegal consequences of this issue will also be important. A potential stop gap measure until the above issues are resolved is not to report VUS with PBGT. Although this limits sensitivity due to some false negatives, in the context of population screening, it can be argued that for a screening programme it is not essential to identify $100 \%$ of individuals at risk.

\section{WHAT ARE THE ECONOMIC CONSEQUENCES OF PBGT?}

As with all new healthcare innovations, it is vital the economic implications are assessed. In order for new strategies and interventions to be sustainable they need to be cost-effective. This is essential for health policy decision-making to enable equitable and effective resource allocation across different types of health interventions. Several studies have sought to evaluate the cost-effectiveness of PBGT. Rubenstein et al showed PBGT for BRCA founder mutations was cost-effective compared to no testing. However, this did not use the standard of care (FH-testing) as the comparator. Manchanda et al published three cost-effectiveness analyses for BRCA testing in the Jewish population, (a) a UK analysis from a randomised trial,[95] (b) a UK and US analysis with varying grandparent ancestry[96] and (c) a Sephardi Jewish analysis[97]. These analysis showed that population-based BRCA testing (compared to FHM) in the Jewish population is highly cost-effective and is cost-saving in most scenarios. . Within 
this community, PBGT was found to improve QALYs and reduce incidence of $\mathrm{OC}(0.34 \%)$ and $\mathrm{BC}$ $(0.62 \%)[95]$.

More recently Manchanda et al. modelled the cost-effectiveness of PBGT for six high and moderaterisk OC and $\mathrm{BC}$ genes (BRCA1, BRCA2, RAD51C, RAD51D, BRIP1, PALB2)[98]. In the UK \& US modelling multi-gene panel testing was more cost-effective than any FHM strategy (compared to FH-based BRCA testing alone or compared to $\mathrm{FH}$-based panel testing). The incremental cost-effectiveness ratio were below the willingness to pay threshold of $£ 30$ '000/QALY (ICER $=f 21^{\prime} 599.96 / \mathrm{QALY}$ ) in the UK, as well as $\$ 100,000 /$ QALY (ICER $=\$ 54769.78)$ in the US. PBGT for this 6-gene panel on probabilistic sensitivity analysis was cost-effective in $83.7 \%$ and $92.7 \%$ simulations for UK and USA health systems respectively.[98] This panel-testing could prevent BC (2420/2386) and OC (657/655) in UK/US women per million [98]. This translates to potentially preventing an additional 17,505 ovarian cancer cases and 64,493 breast cancer cases in UK women, and 65,221 ovarian cancer and 237,610 breast cancer cases in US women. Of late, an Australian study showed that PBGT for BRCA1, BRCA2, MLH1, MSH2, cystic fibrosis (CF), spinal muscular atrophy (SMA), and fragile $X$ syndrome (FXS), in an Australian population was extremely cost-effective (ICER= $7286 \mathrm{AUD} / \mathrm{QALY}) .[99,100]$

\section{SHOULD BOTH WOMEN AND MEN BE OFFERED PBGT IRRESPECTIVE OF AGE?}

The variation in age of eligibility used in economic modelling research is reflected in PBGT trials. Each study had selected age threshold between 18 and 30. Broadly speaking, main differences originate from opposing views on whether PGBT should be available from legally defined adulthood or from the point at which preventative strategies are available [101]. In the UK, based on a FHM genetic testing for CSG is available from 18. Awareness before availability of preventative strategies still has benefit. Receiving a genetic diagnosis is a major event, and time to digest and understand its implications are 
beneficial. Several of the surgical risk options require extensive personal consideration and removing time-pressure from this decision may lead to improved long-term psychological outcomes. Separately, early knowledge enables women to proactively engage in family planning such as making reproductive and contraceptive choices which can impact risk as well as considering pre-implantation genetic diagnosis to prevent continued genetic transmission of the CSG. We argue for testing being made available from the age of 18 years similar to what it is in genetic testing in clinical practice today. Similarly, further discussion regarding maximum age are required. Women over 70 years remain eligible for risk reducing strategies, therefore this upper threshold is punitive. Additionally, older women are likely to have unaffected family members who can benefit from cascade testing and subsequently access preventive interventions to reduce cancer risk. We do not favour an upper age threshold for genetic-testing.

Current PBGT research also varies on gender eligibility. There are several arguments for men receiving PBGT for CSG in this context. For example, men who are BRCA2 carriers can develop breast-cancer, prostate cancer and pancreatic cancer. [102-105]. Additionally, paternal transmission to children is an important consideration, and men should be permitted opportunity for family planning and preimplantation genetic diagnosis. Additionally, men may have other unaffected female relatives who can benefit from cascade testing. These are strong arguments for PBGT to be made available for both men and women.

\section{SOME ETHICAL CONSEQUENCES OF PBGT}

While, there are a host of ethical consequences related to PBGT, we reflect on a few topical issues below. The diagnosis of a CSG mutation represents an increased risk of developing a life-limiting disease. This knowledge can become a substantial psychological and emotional burden[106]. The 
impact of genetic diagnosis on family dynamic are complex, and the guilt of 'passing on' the mutation to relatives is a key source of distress[107, 108]. Occasionally, probands choose not to inform relatives of their diagnosis. This decision has difficult ethical consequences, and causes confliction in a clinician's ability to abide by the fundamental principles of bioethics[109].

Currently, the individual's right to confidentially regarding their genetic results is valued as paramount in clinical practice[110]. Healthcare professionals do not conduct carrier tracing, to identify at risk relatives without the pro-band consents. However, respecting the value of confidentiality negates clinician's ability to apply the principles of non-maleficence to relatives. Within the context of Huntington's disease, this ethical challenge is under legal review in the case $A B C$ vs St Georges Healthcare NHS Trust and others[111].

The General Medical Council recommend that confidentiality is not absolute, and should be violated in cases where 'failure to do so may expose others to risk of death or serious harm'[112]. However, specific guidance on what constitutes 'serious harm' is unavailable. What level of increased risk of ovarian, breast and endometrial cancer would qualify? The issue of VUS management and whether to report it or not has not yet been resolved.

Additionally, individuals with a pathogenic mutation may inadvertently reveal the results of a parent, an 'obligate carrier' who had declined testing. In some instances, this could remove an individual's autonomy to refuse testing.

It is important to establish clear medico-legal guidance regarding these issues as we move towards mainstreaming of PBGT. 


\section{SUMMARY}

PBGT has been proposed as an alternative strategy to the FHM to improve detection in unaffected carriers of CSG who can benefit from precision prevention. Initial studies regarding Ashkenazi Jewish BRCA PBGT testing has prompted global debate about the role of CSG in women's cancer prevention, and more broadly into societal opinions about PBGT[37, 94, 101, 113].

PGBT founder studies demonstrated superior detection of pathogenic mutations in unaffected individuals[23,65]. Diagnosis was demonstrated to result in excellent uptake of cancer preventative strategies[81, 85]. Overall compared to FHM this was associated with reduced anxiety in the population and did not cause psychological harm.[40] The Psychological impact in those testing positive appeared transient as is seen in those testing positive from high risk clinics. [40, 81] The PBGT process was associated with high satisfaction rates (90-95\%) and a high proportion of AJ communities were supportive of PBGT $[76,88,114]$. This strategy is cost-effective and it is high time policy changed to offering PBGT in the Jewish population.

Clearly the experience of founder-populations alone is not directly applicable to the broader general society. Fundamentally, the difference in prevalence and subsequent health burden is influential. It needs to be established whether the wider general population would be as driven to participate in PBGT for women's cancer prevention and whether the outcomes and health impact in them will be similar.

Undeniably public awareness of genetic cancer predisposition has surged with the aid of celebrity and political endorsements[115]. Additionally, the multi-million-pound industry of direct-to-consumer 
genetic tests is testament to an increasing appetite for knowledge of personal genetics. Whether this interest will be cross-sectional across society is not known.

Significant logistical questions regarding the national implementation of PBGT remain. Consensus regarding eligibility criteria, genetic counselling/education protocol, and VUS management represent some of the major issues which require addressing. It is likely we will need different models/pathways for different health systems which are context specific.

PBGT for CSG has been demonstrated to have important health-empowering benefits. The ability to improve identification of unaffected carriers is promising, and potential to reduce the morbidity and mortality of women's cancer is clear. Therefore, despite the logistical challenges, translational work must continue to focus on the integration of cancer-susceptibility genes into population healthcare, promoting precision medicine.

\section{PRACTICE POINTS}

- $50-60 \%$ of patients with a BRCA mutation are not eligible for genetic-testing and are missed through the FHM[23-25].

- PGBT founder studies demonstrated superior detection of pathogenic mutations in unaffected individuals[23, 65].

- Psychological consequences of detection of CSG from PBGT appear comparable to those detected in a FHM.

\section{RESEARCH AGENDA}


- The outcomes and acceptability of conducting PBGT for CSGs in low risk populations.

- Further reflect the large variation of CSGs with validated clinical utility, including BRCA1, BRCA2, PALB2, RAD51C, RAD51D, BRIP1, MLH1, MSH2 and MSH6.

- Evaluating more complex risk adapted modelling strategies for population stratification for targeted screening and prevention.

- The optimum structure of genetic counselling service to accompany PBGT

\section{ACKNOWLEDGEMENTS}

No funding was received for this review

\section{CONFLICT OF INTEREST}

RM is supported by an NHS Innovation Accelerator (NIA) Fellowship and by The Eve Appeal. RM declares research funding from Barts \& the London Charity and Rosetrees Trust outside this work, an honorarium for grant review from Israel National Institute for Health Policy Research and honorarium for advisory board membership from Astrazeneca/MSD. 


\section{MULTIPLE CHOICE QUETIONS}

\section{Question 1}

1. Population-Based Genetic Testing (PBGT) for founder BRCA1 \& BRCA2 mutations in the Ashkenazi Jewish community:

A. Has an acceptability level of 34-40\%, evidenced by current research studies.

B. Has been found to be cost-saving compared to family-history model, when analysed by economic decision models.

C. Is less effective at detecting unaffected carriers than a family history model.

D. Utilises next generation sequencing methods to analysis the entire BRCA1 and BRCA2 genes

E. Has been explored due to the high prevalence of these mutations (1 in 200) within this population.

\section{Answers to Question 1}

$\mathrm{A}=$ False; $\mathrm{B}=$ True; $\mathrm{C}=$ False; $\mathrm{D}=$ False; $\mathrm{E}=$ False

\section{Explanation to Question 1}

A. This is incorrect as research studies have demonstrated higher levels of acceptability $(90-95 \%)$ in the Ashkenazi Jewish Community for PBGT of $B R C A 1 \& B R C A 2$ founder mutations. $[23,77,88,116]$. B. Manchanda et al demonstrated that PBGT is cost-saving with a baseline discounted incremental cost-effectiveness ration of $-£ 2079 / Q A L Y$ when compared to the existing family history model[95]. C. This is incorrect, PBGT has been demonstrated to detected 50-56\% more pathogenic mutations carriers than the family history model[23-25]. This is due to the stringent family history criteria which must be achieved before genetic testing is offered in the current system. PBGT does not have such restrictive barriers.

D. Actually, genetic testing for founder mutations does not involve analysis of the entire genes. In clinical practice and in research settings, polymerase chain reaction tools or exome analysis are used to identify the three common founder mutations (BRCA1 5382insC, 185delAG mutation, and BRCA2 6174delT) which are present in Ashkenazi Jewish community [20, 23, 25, 39]. 
E. This is false because the aforementioned founder mutations are present in 1:40 members of the Ashkenazi Jewish community[61, 62].

\section{Question 2}

2. Research studies have demonstrated the following psychological consequences of PBGT in Ashkenazi Jewish Community:

A. Cancer-related distress is better in mutation carriers at one year following results

B. Quality of life is better in those who underwent family history genetic testing rather than PBGT

C. Anxiety and depression increases in the three years following PBGT compared to family history model.

D. Anxiety decreases in the long-term following PBGT compared to the family history model

E. PBGT resulted in more long-term uncertainty than a family-history model of testing

\section{Answers to Questions 2}

$\mathrm{A}=$ False $; \mathrm{B}=$ False $\mathrm{C}=$ False $\mathrm{D}=$ True; $\mathrm{E}=$ False

\section{Explanation to Question 2}

A . Unsurprisingly Metcalfe et al. found cancer-related distress was worse in the one year following pathogenic mutation was found. However, this was a small cohort (18 x carriers) so more work is required to clearly outline the short-term psychological consequences upon carriers after PBGT[77]. B. This is incorrect as Manchanda et al. demonstrated that there was no statistically significant difference in overall quality of life scores between the PBGT-arm and the family history-arm of a randomised controlled trial. C. Contrast tests showed a statistically significant decrease in overall HADS ( $p=-0.0012)$ scores in the PS arm compared with the FH arm over three years. D. Metcalfe et al. and Manchanda et al. group demonstrated that the decrease in anxiety observed after $B R C A$ testing was maintained into the long-term[40, 81]. This was more significant for PBGT-arm versus those who had testing via a family history model[40]. E. Manchanda et al. found that there was no statistically significant difference in long-term uncertainty for PBGT (MICRA uncertainty score mean 
2.9 (Standard error $=0.24$ ) compared to a family-history model (MICRA uncertainty score mean 3.8(Standard error $=0.57)[40]$.

\section{Question 3}

3. What is cascade genetic testing for cancer susceptibility genes (CSG)?

A. Offering a multi-gene panel based on the type of cancers present in a family history

B. Offering full BRCA gene analysis via next generation sequencing rather than only the three Ashkenazi Jewish Founder mutations

C. Genetic testing for cancer susceptibility genes which is offered to patients following a cancer diagnosis

D. Offering at-risk family members genetic testing for CSG mutation after it has been located in a relative

E. Sequential analysis of individual cancer susceptibility genes until a pathogenic mutation is identified

\section{Answers to Question 3}

Answer: A-False, B-False, C-False, D - True, E- False

\section{Explanation to Question 3}

A. Cascade testing does not refer to the multi-gene panel process.

B. Cascade testing does not refer to the type of genetic analysis genes undergo for detection.

C. Cascade testing does not refer to the process of offering patients a genetic testing after cancer diagnosis.

D. Cascade testing is the systematic process of offering genetic testing to biologic relatives of a proband once a pathogenic variant[117].

E. The sequential analysis of different CSG is not cascade testing. 


\section{REFERENCES}

1. Moore K, Colombo N, Scambia G, Kim BG, Oaknin A, Friedlander M, et al. Maintenance Olaparib in Patients with Newly Diagnosed Advanced Ovarian Cancer. N Engl J Med. 2018;379(26):2495-505.

2. UK CR. Cancer incidence for common cancers. https://www.cancerresearchuk.org/healthprofessional/cancer-statistics/incidence/common-cancers-compared\#heading-Two; 2019.

3. Ryan NAJ, Glaire MA, Blake D, Cabrera-Dandy M, Evans DG, Crosbie EJ. The proportion of endometrial cancers associated with Lynch syndrome: a systematic review of the literature and meta-analysis. Genet Med. 2019.

4. Walsh T, Casadei S, Lee MK, Pennil CC, Nord AS, Thornton AM, et al. Mutations in 12 genes for inherited ovarian, fallopian tube, and peritoneal carcinoma identified by massively parallel sequencing. Proc Natl Acad Sci U S A. 2011;108(44):18032-7.

5. Bradbury AR, Olopade OI. Genetic susceptibility to breast cancer. Rev Endocr Metab Disord. 2007;8(3):255-67.

6. Harter P, Hauke J, Heitz F, Reuss A, Kommoss S, Marme F, et al. Prevalence of deleterious germline variants in risk genes including BRCA1/2 in consecutive ovarian cancer patients (AGO-TR-1). PLoS One. 2017;12(10):e0186043.

7. Childers CP, Childers KK, Maggard-Gibbons M, Macinko J. National Estimates of Genetic Testing in Women With a History of Breast or Ovarian Cancer. J Clin Oncol. 2017;35(34):3800-6. 8. Kauff ND, Domchek SM, Friebel TM, Robson ME, Lee J, Garber JE, et al. Risk-reducing salpingo-oophorectomy for the prevention of BRCA1- and BRCA2-associated breast and gynecologic cancer: a multicenter, prospective study. J Clin Oncol. 2008;26(8):1331-7.

9. Burn J, Gerdes A-M, Macrae F, Mecklin J-P, Moeslein G, Olschwang S, et al. Long-term effect of aspirin on cancer risk in carriers of hereditary colorectal cancer: an analysis from the CAPP2 randomised controlled trial. Lancet (London, England). 2011;378(9809):2081-7.

10. Kotsopoulos J. BRCA Mutations and Breast Cancer Prevention. Cancers. 2018;10(12):524.

11. Domchek SM, Friebel TM, Singer CF, Evans DG, Lynch HT, Isaacs C, et al. Association of RiskReducing Surgery in BRCA1 or BRCA2 Mutation Carriers With Cancer Risk and Mortality. Jama-J Am Med Assoc. 2010;304(9):967-75.

12. NICE. Familial breast cancer: classification and care of people at risk of familial breast cancer and management of breast cancer and related risks in people with a family history of breast cancer. In: excellence NifHac, editor. London, UK2013.

13. Griffith GL, Edwards RT, Gray J. Cancer genetics services: a systematic review of the economic evidence and issues. British Journal of Cancer. 2004;90(9):1697-703.

14. Hann KEJ, Freeman M, Fraser L, Waller J, Sanderson SC, Rahman B, et al. Awareness, knowledge, perceptions, and attitudes towards genetic testing for cancer risk among ethnic minority groups: a systematic review. BMC Public Health. 2017;17(1):503.

15. Armstrong K, Micco E, Carney A, Stopfer J, Putt M. Racial Differences in the Use of BRCA1/2 Testing Among Women With a Family History of Breast or Ovarian Cancer. JAMA.

2005;293(14):1729-36.

16. Childers KK, Maggard-Gibbons M, Macinko J, Childers CP. National Distribution of Cancer Genetic Testing in the United States: Evidence for a Gender Disparity in Hereditary Breast and Ovarian Cancer. JAMA Oncology. 2018;4(6):876-9.

17. Martin AP, Pedra G, Downing J, Collins B, Godman B, Alfirevic A, et al. Trends in BRCA testing and socioeconomic deprivation. Eur J Hum Genet. 2019;27(9):1351-60.

18. Manchanda R, Burnell M, Gaba F, Sanderson S, Loggenberg K, Gessler S, et al. Attitude towards and factors affecting uptake of population-based BRCA testing in the Ashkenazi Jewish population: a cohort study. Bjog. 2019;126(6):784-94.

19. Lewis MJ, Peterson SK. Perceptions of genetic testing for cancer predisposition among Ashkenazi Jewish women. Community Genet. 2007;10(2):72-81. 
20. Metcalfe KA, Poll A, Royer R, Llacuachaqui $M$, Tulman A, Sun P, et al. Screening for founder mutations in BRCA1 and BRCA2 in unselected Jewish women. J Clin Oncol. 2010;28(3):387-91.

21. Golmard L, Delnatte C, Laugé A, Moncoutier V, Lefol C, Abidallah K, et al. Breast and ovarian cancer predisposition due to de novo BRCA1 and BRCA2 mutations. Oncogene. 2016;35(10):1324-7. 22. Win AK, Jenkins MA, Buchanan DD, Clendenning M, Young JP, Giles GG, et al. Determining the frequency of de novo germline mutations in DNA mismatch repair genes. Journal of medical genetics. 2011;48(8):530-4.

23. Manchanda R, Loggenberg K, Sanderson S, Burnell M, Wardle J, Gessler S, et al. Population testing for cancer predisposing BRCA1/BRCA2 mutations in the Ashkenazi-Jewish community: a randomized controlled trial. J Natl Cancer Inst. 2015;107(1):379.

24. Moller P, Hagen Al, Apold J, Maehle L, Clark N, Fiane B, et al. Genetic epidemiology of BRCA mutations--family history detects less than $50 \%$ of the mutation carriers. Eur J Cancer. 2007;43(11):1713-7.

25. Gabai-Kapara E, Lahad A, Kaufman B, Friedman E, Segev S, Renbaum P, et al. Populationbased screening for breast and ovarian cancer risk due to BRCA1 and BRCA2. Proc Natl Acad Sci U S A. 2014;111(39):14205-10.

26. Antoniou AC, Cunningham AP, Peto J, Evans DG, Lalloo F, Narod SA, et al. The BOADICEA model of genetic susceptibility to breast and ovarian cancers: updates and extensions. Br J Cancer. 2008;98(8):1457-66.

27. Evans DG, Lalloo F, Cramer A, Jones EA, Knox F, Amir E, et al. Addition of pathology and biomarker information significantly improves the performance of the Manchester scoring system for BRCA1 and BRCA2 testing. J Med Genet. 2009;46(12):811-7.

28. Mazzola E, Chipman J, Cheng SC, Parmigiani G. Recent BRCAPRO upgrades significantly improve calibration. Cancer Epidemiol Biomarkers Prev. 2014;23(8):1689-95.

29. Evans DG, Harkness EF, Plaskocinska I, Wallace AJ, Clancy T, Woodward ER, et al. Pathology update to the Manchester Scoring System based on testing in over 4000 families. J Med Genet. 2017;54(10):674-81.

30. Lee A, Mavaddat N, Wilcox AN, Cunningham AP, Carver T, Hartley S, et al. BOADICEA: a comprehensive breast cancer risk prediction model incorporating genetic and nongenetic risk factors. Genet Med. 2019;21(8):1708-18.

31. Manchanda R, Blyuss O, Gaba F, Gordeev VS, Jacobs C, Burnell M, et al. Current detection rates and time-to-detection of all identifiable BRCA carriers in the Greater London population. J Med Genet. 2018;55(8):538-45.

32. Hampel $\mathrm{H}$, de la Chapelle $\mathrm{A}$. The search for unaffected individuals with Lynch syndrome: do the ends justify the means? Cancer prevention research (Philadelphia, Pa). 2011;4(1):1-5.

33. Singh H, Schiesser R, Anand G, Richardson PA, El-Serag HB. Underdiagnosis of Lynch Syndrome Involves More Than Family History Criteria. Clinical Gastroenterology and Hepatology. 2010;8(6):523-9.

34. UK NSC. Criteria for appraising the viability, effectiveness and appropriateness of a screening programme: UK National Screening Committee; 2015 [Available from:

https://www.gov.uk/government/publications/evidence-review-criteria-national-screening-

programmes/criteria-for-appraising-the-viability-effectiveness-and-appropriateness-of-a-screeningprogramme.

35. Khoury MJ, McCabe LL, McCabe ER. Population screening in the age of genomic medicine. N Engl J Med. 2003;348(1):50-8.

36. Burke W, Zimmerman R. Moving beyond ACCE: An Expanded Framework for Genetic Test Evaluation2007:[http://www.phgfoundation.org/file/16270/ p.]. Available from: http://www.phgfoundation.org/file/16270/.

37. Manchanda R, Jacobs I. Genetic screening for gynecological cancer: where are we heading? Future Oncol. 2015. 
38. CDC. ACCE Model Process for Evaluating Genetic Tests. Genomic Testing [Internet]. 2010:[http://www.cdc.gov/genomics/gtesting/ACCE/ p.]. Available from: http://www.cdc.gov/genomics/gtesting/ACCE/.

39. Richards CS, Ward PA, Roa BB, Friedman LC, Boyd AA, Kuenzli G, et al. Screening for 185 delAG in the Ashkenazim. American journal of human genetics. 1997;60(5):1085-98.

40. Manchanda R, Burnell M, Gaba F, Desai R, Wardle J, Gessler S, et al. Randomised trial of population-based BRCA testing in Ashkenazi Jews: long-term outcomes. Bjog. 2019.

41. Akbari MR, Gojska N, Narod SA. Coming of age in Canada: a study of population-based genetic testing for breast and ovarian cancer. Current oncology (Toronto, Ont). 2017;24(5):282-3. 42. PROMISE. Predicting risk of ovarian malignancy improved screening and early detection feasibility study. May 2017 to May 2024.

43. Easton DF, Bishop DT, Ford D, Crockford GP. Genetic linkage analysis in familial breast and ovarian cancer: results from 214 families. The Breast Cancer Linkage Consortium. Am J Hum Genet. 1993;52(4):678-701.

44. Easton DF, Ford D, Bishop DT. Breast and ovarian cancer incidence in BRCA1-mutation carriers. Breast Cancer Linkage Consortium. Am J Hum Genet. 1995;56(1):265-71.

45. Kuchenbaecker KB, Hopper JL, Barnes DR, Phillips KA, Mooij TM, Roos-Blom MJ, et al. Risks of Breast, Ovarian, and Contralateral Breast Cancer for BRCA1 and BRCA2 Mutation Carriers. JAMA. 2017;317(23):2402-16.

46. Moller P, Seppala TT, Bernstein I, Holinski-Feder E, Sala P, Gareth Evans D, et al. Cancer risk and survival in path_MMR carriers by gene and gender up to 75 years of age: a report from the Prospective Lynch Syndrome Database. Gut. 2018;67(7):1306-16.

47. Loveday C, Turnbull C, Ruark E, Xicola RM, Ramsay E, Hughes D, et al. Germline RAD51C mutations confer susceptibility to ovarian cancer. Nat Genet. 2012;44(5):475-6; author reply 6.

48. Loveday C, Turnbull C, Ramsay E, Hughes D, Ruark E, Frankum JR, et al. Germline mutations in RAD51D confer susceptibility to ovarian cancer. Nat Genet. 2011;43(9):879-82.

49. Ramus SJ, Song H, Dicks E, Tyrer JP, Rosenthal AN, Intermaggio MP, et al. Germline Mutations in the BRIP1, BARD1, PALB2, and NBN Genes in Women With Ovarian Cancer. J Natl Cancer Inst. 2015;107(11).

50. Yang X, Leslie G, Doroszuk A, Schneider S, Allen J, Decker B, et al. Cancer Risks Associated With Germline PALB2 Pathogenic Variants: An International Study of 524 Families. J Clin Oncol. 2019:JCO1901907.

51. Kurian AW, Ward KC, Howlader N, Deapen D, Hamilton AS, Mariotto A, et al. Genetic Testing and Results in a Population-Based Cohort of Breast Cancer Patients and Ovarian Cancer Patients. J Clin Oncol. 2019;37(15):1305-15.

52. Buys SS, Sandbach JF, Gammon A, Patel G, Kidd J, Brown KL, et al. A study of over 35,000 women with breast cancer tested with a 25 -gene panel of hereditary cancer genes. Cancer. 2017;123(10):1721-30.

53. Modan B, Hartge P, Hirsh-Yechezkel G, Chetrit A, Lubin F, Beller U, et al. Parity, oral contraceptives, and the risk of ovarian cancer among carriers and noncarriers of a BRCA1 or BRCA2 mutation. N Engl J Med. 2001;345(4):235-40.

54. Moslehi R, Chu W, Karlan B, Fishman D, Risch H, Fields A, et al. BRCA1 and BRCA2 mutation analysis of 208 Ashkenazi Jewish women with ovarian cancer. Am J Hum Genet. 2000;66(4):1259-72.

55. King MC, Marks JH, Mandell JB, Grp NYBCS. Breast and ovarian cancer risks due to inherited mutations in BRCA1 and BRCA2. Science. 2003;302(5645):643-6.

56. Kurian AW, Hughes E, Handorf E, Gutin A, Allen B, Hartman AR, et al. Breast and Ovarian Cancer Penetrance Estimates Derived From Germline Multiple-Gene Sequencing Results in Women. JCO Precision Oncology 2017(1):1-12.

57. Lilyquist J, LaDuca H, Polley E, Davis BT, Shimelis H, Hu C, et al. Frequency of mutations in a large series of clinically ascertained ovarian cancer cases tested on multi-gene panels compared to reference controls. Gynecol Oncol. 2017;147(2):375-80. 
58. Jervis $\mathrm{S}$, Song $\mathrm{H}$, Lee $\mathrm{A}$, Dicks $\mathrm{E}$, Harrington $\mathrm{P}$, Baynes $\mathrm{C}$, et al. A risk prediction algorithm for ovarian cancer incorporating BRCA1, BRCA2, common alleles and other familial effects. J Med Genet. 2015.

59. Manickam K, Buchanan AH, Schwartz MLB, Hallquist MLG, Williams JL, Rahm AK, et al. Exome Sequencing-Based Screening for BRCA1/2 Expected Pathogenic Variants Among Adult Biobank Participants. JAMA Netw Open. 2018;1(5):e182140.

60. Hampel $\mathrm{H}$, de la Chapelle A. How do we approach the goal of identifying everybody with Lynch Syndrome?. Familial Cancer

61. Struewing JP, Hartge P, Wacholder S, Baker SM, Berlin M, McAdams M, et al. The risk of cancer associated with specific mutations of BRCA1 and BRCA2 among Ashkenazi Jews. N Engl J Med. 1997;336(20):1401-8.

62. Roa BB, Boyd AA, Volcik K, Richards CS. Ashkenazi Jewish population frequencies for common mutations in BRCA1 and BRCA2. Nat Genet. 1996;14(2):185-7.

63. Hartge P, Struewing JP, Wacholder S, Brody LC, Tucker MA. The prevalence of common BRCA1 and BRCA2 mutations among Ashkenazi Jews. Am J Hum Genet. 1999;64(4):963-70.

64. Gronwald J, Huzarski T, Byrski T, Debniak T, Metcalfe K, Narod SA, et al. Direct-to-patient BRCA1 testing: the Twoj Styl experience. Breast Cancer Res Treat. 2006;100(3):239-45.

65. Metcalfe KA, Poll A, Royer R, Nanda S, Llacuachaqui M, Sun P, et al. A comparison of the detection of BRCA mutation carriers through the provision of Jewish population-based genetic testing compared with clinic-based genetic testing. Br J Cancer. 2013;109(3):777-9.

66. George A, Riddell D, Seal S, Talukdar S, Mahamdallie S, Ruark E, et al. Implementing rapid, robust, cost-effective, patient-centred, routine genetic testing in ovarian cancer patients. Sci Rep. 2016;6:29506.

67. Prapa $\mathrm{M}$, Solomons J, Tischkowitz $\mathrm{M}$. The use of panel testing in familial breast and ovarian cancer. Clin Med (Lond). 2017;17(6):568-72.

68. CDC. ACCE Model Process for Evaluating Genetic Tests. Genomic Testing. . Atlanta, USA: The Office of Public Health Genomics (OPHG), Centers for Disease Control and Prevention (CDC); 2010.

69. Ramus SJ, Song H, Dicks E, Tyrer JP, Rosenthal AN, Intermaggio MP, et al. Germline Mutations in the BRIP1, BARD1, PALB2, and NBN Genes in Women With Ovarian Cancer. J Natl Cancer Inst. 2015;107(11).

70. Song H, Dicks E, Ramus SJ, Tyrer JP, Intermaggio MP, Hayward J, et al. Contribution of Germline Mutations in the RAD51B, RAD51C, and RAD51D Genes to Ovarian Cancer in the Population. J Clin Oncol. 2015;33(26):2901-7.

71. Rowley SM, Mascarenhas L, Devereux L, Li N, Amarasinghe KC, Zethoven M, et al. Population-based genetic testing of asymptomatic women for breast and ovarian cancer susceptibility. Genet Med. 2019;21(4):913-22.

72. Stratton MR, Rahman N. The emerging landscape of breast cancer susceptibility. Nature Genetics. 2008;40(1):17-22.

73. Loveday C, Turnbull C, Ramsay E, Hughes D, Ruark E, Frankum JR, et al. Germline mutations in RAD51D confer susceptibility to ovarian cancer. Nature Genetics. 2011;43(9):879-82.

74. Meindl A, Hellebrand H, Wiek C, Erven V, Wappenschmidt B, Niederacher D, et al. Germline mutations in breast and ovarian cancer pedigrees establish RAD51C as a human cancer susceptibility gene. Nature Genetics. 2010;42(5):410-4.

75. Schwartz MD, Valdimarsdottir HB, Peshkin BN, Mandelblatt J, Nusbaum R, Huang A-T, et al. Randomized noninferiority trial of telephone versus in-person genetic counseling for hereditary breast and ovarian cancer. Journal of clinical oncology : official journal of the American Society of Clinical Oncology. 2014;32(7):618-26.

76. Manchanda R, Burnell M, Loggenberg K, Desai R, Wardle J, Sanderson SC, et al. Clusterrandomised non-inferiority trial comparing DVD-assisted and traditional genetic counselling in systematic population testing for BRCA1/2 mutations. J Med Genet. 2016;53(7):472-80. 
77. Metcalfe KA, Poll A, Llacuachaqui M, Nanda S, Tulman A, Mian N, et al. Patient satisfaction and cancer-related distress among unselected Jewish women undergoing genetic testing for BRCA1 and BRCA2. Clin Genet. 2010;78(5):411-7.

78. Manchanda R. Predicting risk of ovarian malignancy improved screening and early detection feasibility study ISRCTN Registry: ISRCTN54246466 [Internet]. 2017 2.7.17. Available from: http://www.isrctn.com/ISRCTN54246466.

79. Yuen J, Cousens N, Barlow-Stewart K, O'Shea R, Andrews L. Online BRCA1/2 screening in the Australian Jewish community: a qualitative study. J Community Genet. 2019.

80. Manchanda R, Burnell M, Abdelraheim A, Johnson M, Sharma A, Benjamin E, et al. Factors influencing uptake and timing of risk reducing salpingo-oophorectomy in women at risk of familial ovarian cancer: a competing risk time to event analysis. BJOG. 2012;119(5):527-36.

81. Metcalfe KA, Mian N, Enmore M, Poll A, Llacuachaqui M, Nanda S, et al. Long-term follow-up of Jewish women with a BRCA1 and BRCA2 mutation who underwent population genetic screening. Breast Cancer Res Treat. 2012;133(2):735-40.

82. Metcalfe K, Eisen A, Senter L, Armel S, Bordeleau L, Meschino WS, et al. International trends in the uptake of cancer risk reduction strategies in women with a BRCA1 or BRCA2 mutation. British Journal of Cancer. 2019;121(1):15-21.

83. Skytte AB, Gerdes AM, Andersen MK, Sunde L, Brondum-Nielsen K, Waldstrom M, et al. Riskreducing mastectomy and salpingo-oophorectomy in unaffected BRCA mutation carriers: uptake and timing. Clin Genet. 2010;77(4):342-9.

84. Manchanda R, Menon U. Setting the Threshold for Surgical Prevention in Women at Increased Risk of Ovarian Cancer. Int J Gynecol Cancer. 2018;28(1):34-42.

85. Plon SE, Peterson LE, Friedman LC, Richards CS. Mammography behavior after receiving a negative BRCA1 mutation test result in the Ashkenazim: a community-based study. Genet Med. 2000;2(6):307-11.

86. Lieberman S, Tomer A, Ben-Chetrit A, Olsha O, Strano S, Beeri R, et al. Population screening for BRCA1/BRCA2 founder mutations in Ashkenazi Jews: proactive recruitment compared with selfreferral. Genet Med. 2016:10.1038/gim.2016.182.

87. Hall MA, McEwen JE, Barton JC, Walker AP, Howe EG, Reiss JA, et al. Concerns in a primary care population about genetic discrimination by insurers. Genetics in Medicine. 2005;7(5):311-6.

88. Cousens N, Kaur R, Meiser B, Andrews L. Community attitudes towards a Jewish community BRCA1/2 testing program. Fam Cancer. 2017;16(1):17-28.

89. Lehmann LS, Weeks JC, Klar N, Garber JE. A population-based study of Ashkenazi Jewish women's attitudes toward genetic discrimination and BRCA1/2 testing. Genet Med. 2002;4(5):34652.

90. Walsh T, Lee MK, Casadei S, Thornton AM, Stray SM, Pennil C, et al. Detection of inherited mutations for breast and ovarian cancer using genomic capture and massively parallel sequencing. Proc Natl Acad Sci U S A. 2010;107(28):12629-33.

91. Yurgelun MB, Hiller E, Garber JE. Population-Wide Screening for Germline BRCA1 and BRCA2 Mutations: Too Much of a Good Thing? J Clin Oncol. 2015;33(28):3092-5.

92. Rebbeck TR, Halbert CH, Sankar P. Genetics, epidemiology, and cancer disparities: is it black and white? J Clin Oncol. 2006;24(14):2164-9.

93. Hall MJ, Olopade Ol. Disparities in genetic testing: thinking outside the BRCA box. J Clin Oncol. 2006;24(14):2197-203.

94. King MC, Levy-Lahad E, Lahad A. Population-based screening for BRCA1 and BRCA2: 2014 Lasker Award. JAMA. 2014;312(11):1091-2.

95. Manchanda R, Legood R, Burnell M, McGuire A, Raikou M, Loggenberg K, et al. Costeffectiveness of population screening for BRCA mutations in Ashkenazi jewish women compared with family history-based testing. J Natl Cancer Inst. 2015;107(1):380. 
96. Manchanda R, Patel S, Antoniou AC, Levy-Lahad E, Turnbull C, Evans DG, et al. Costeffectiveness of population based BRCA testing with varying Ashkenazi Jewish ancestry. Am J Obstet Gynecol. 2017;217(5):578 e1- e12.

97. Patel S, Legood R, Evans DG, Turnbull C, Antoniou AC, Menon U, et al. Cost effectiveness of population based BRCA1 founder mutation testing in Sephardi Jewish women. Am J Obstet Gynecol. 2018;218(4):431 e1- e12.

98. Manchanda R, Patel S, Gordeev VS, Antoniou AC, Smith S, Lee A, et al. Cost-effectiveness of Population-Based BRCA1, BRCA2, RAD51C, RAD51D, BRIP1, PALB2 Mutation Testing in Unselected General Population Women. J Natl Cancer Inst. 2018;110(7):714-25.

99. Lacaze P, Tiller J, Bao Y, Riaz M, Winship I, Zhang L. Response to Veenstra et al. Genet Med. 2019;21(12):2842-3.

100. Zhang L, Bao Y, Riaz M, Tiller J, Liew D, Zhuang X, et al. Population genomic screening of all young adults in a health-care system: a cost-effectiveness analysis. Genet Med. 2019;21(9):1958-68. 101. Metcalfe KA, Eisen A, Lerner-Ellis J, Narod SA. Is it time to offer BRCA1 and BRCA2 testing to all Jewish women? Curr Oncol. 2015;22(4):e233-6.

102. Møller P, Seppälä TT, Bernstein I, Holinski-Feder E, Sala P, Gareth Evans D, et al. Cancer risk and survival in <em>path_MMR</em> carriers by gene and gender up to 75 years of age: a report from the Prospective Lynch Syndrome Database. Gut. 2018;67(7):1306-16.

103. Takeuchi S, Doi M, Ikari N, Yamamoto M, Furukawa T. Mutations in BRCA1, BRCA2, and PALB2, and a panel of 50 cancer-associated genes in pancreatic ductal adenocarcinoma. Scientific Reports. 2018;8(1):8105.

104. Castro E, Eeles R. The role of BRCA1 and BRCA2 in prostate cancer. Asian J Androl. 2012;14(3):409-14.

105. Silvestri V, Barrowdale D, Mulligan AM, Neuhausen SL, Fox S, Karlan BY, et al. Male breast cancer in BRCA1 and BRCA2 mutation carriers: pathology data from the Consortium of Investigators of Modifiers of BRCA1/2. Breast Cancer Res. 2016;18(1):15.

106. Watson M, Foster C, Eeles R, Eccles D, Ashley S, Davidson R, et al. Psychosocial impact of breast/ovarian (BRCA 1/2) cancer-predictive genetic testing in a UK multi-centre clinical cohort. British Journal of Cancer. 2004;91(10):1787-94.

107. Lynch HT, Snyder C, Lynch JF, Karatoprakli P, Trowonou A, Metcalfe K, et al. Patient responses to the disclosure of BRCA mutation tests in hereditary breast-ovarian cancer families. Cancer Genetics and Cytogenetics. 2006;165(2):91-7.

108. Surbone A. Ethical implications of genetic testing for breast cancer susceptibility. Critical Reviews in Oncology/Hematology. 2001;40(2):149-57.

109. Gillon R. Medical ethics: four principles plus attention to scope. BMJ. 1994;309(6948):184.

110. Dove ES, Chico V, Fay M, Laurie G, Lucassen AM, Postan E. Familial genetic risks: how can we better navigate patient confidentiality and appropriate risk disclosure to relatives? J Med Ethics. 2019;45(8):504-7.

111. Narod SA. Breast cancer prevention in the era of precision medicine. J Natl Cancer Inst. 2015;107(5).

112. Council. GM. Confidentiality: good practice in handling patient information: General Medical Council 2017, revised in May 2018.

113. Manchanda R, Gaba F. A commentary on population genetic testing for primary prevention: changing landscape and the need to change paradigm. BJOG. 2019;126(6):686-9.

114. Lieberman S, Lahad A, Tomer A, Cohen C, Levy-Lahad E, Raz A. Population screening for BRCA1/BRCA2 mutations: lessons from qualitative analysis of the screening experience. Genet Med. 2017;19(6):628-34.

115. Jolie A. My Medical Choice. The New York Times. 2013 May 14th 2013;Sect. Section A.

116. Lieberman S, Tomer A, Ben-Chetrit A, Olsha O, Strano S, Beeri R, et al. Population screening for BRCA1/BRCA2 founder mutations in Ashkenazi Jews: proactive recruitment compared with selfreferral. Genet Med. 2017;19(7):754-62. 
117. NCl. National Cancer Institute Dictionary of Genetics Terms: National Institutes of Health; 2019 [Available from: https://www.cancer.gov/publications/dictionaries/genetics-

dictionary/def/cascade-screening. 